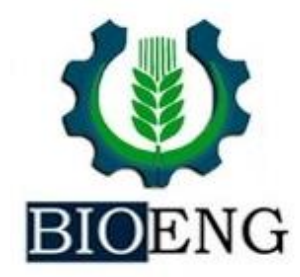

\title{
RENDIMENTO DE GRÃOS DE MILHO IRRIGADO POR GOTEJAMENTO SUBTERRÂNEO E ESTIMATIVA DA IRRIGAÇÃO COM DADOS DA PREVISÃO DO TEMPO
}

\author{
Z. B. de Oliveira*
}

\author{
UFSM - Universidade Federal de Santa Maria, RS, Brasil
}

Article history: Received 20 December 2017; Received in revised form 07 March 2018; Accepted 17 March 2018; Available online 27 March 2018.

\begin{abstract}
RESUMO
O presente trabalho teve como objetivos avaliar o rendimento de grãos do milho irrigado por gotejamento subterrâneo instalado em duas profundidades e dois espaçamentos entrelinhas e, comparar as irrigações realizadas com dados meteorológicos medidos com irrigações estimadas utilizando dados da previsão do tempo. O trabalho foi realizado no ano agrícola 2013/14 em Júlio de Castilhos -RS, em três etapas: uma de campo para a análise de dados culturais, uma para a estimativa da ETo com dados da previsão do tempo (ETo prev) e uma para a estimativa da necessidade de irrigação a partir da ETo prev e da ETo calculada com dados meteorológicos medidos (ETo). As estimativas da ETo, da ETo prev e da necessidade de irrigação seguiram as recomendações do boletim FAO - 56. O maior rendimento de grãos $\left(1.1895,34 \mathrm{~kg} \mathrm{ha}^{-1}\right)$ foi observado utilizando tubogotejadores instalados $40 \mathrm{~cm}$ de profundidade. O erro quadrático médio (RMSE) da ETo prev em comparação a ETo foi de $1,05 \mathrm{~mm} \mathrm{dia}^{-1}$, indicando uma boa concordância entre valores estimados e valores observados. O número de irrigações recomendadas com a ETo e a ETo prev foi o mesmo (8 irrigações), demostrando que a utilização de dados da previsão meteorológica para o manejo da irrigação, pode ser uma alternativa para locais em que dados meteorológicos medidos são indisponíveis.
\end{abstract}

Palavras-chave: necessidade de irrigação; gotejamento subterrâneo; previsão do tempo.

\section{YIELD OF CORN GRANTS IRRIGATED BY UNDERGROUND DRIPPING AND ESTIMATION OF IRRIGATION WITH TIME FORECAST DATA}

\begin{abstract}
The objective of the present work was to evaluate the yield of grains of drip irrigated maize installed at two depths and two spacings between rows and to compare the irrigations performed with measured meteorological data with irrigations estimated using data from the weather forecast. The work was carried out in the agricultural year 2013/14 in Júlio de Castilhos-RS, in three stages: a field for the analysis of cultural data, one for the estimation of ETo with data of the weather forecast (ETo prev) and one for the estimate of the need for irrigation from ETo prev and ETo calculated with measured meteorological data (ETo). Estimates of ETo, ETo prev and the need for irrigation followed the recommendations of the FAO - 56 bulletin. The highest grain yield $\left(1,1895.34 \mathrm{~kg}^{\text {ha }}{ }^{-1}\right)$ was observed using tubers installed $40 \mathrm{~cm}$ deep. The mean square error (RMSE) of ETo predicted in comparison to ETo was $1.05 \mathrm{~mm} \mathrm{dia}{ }^{-1}$, indicating a good agreement between estimated values and observed values. The number of recommended irrigations with ETo and ETo prev was the same (8 irrigations), showing that the use of weather forecast data for irrigation management may be an alternative to locations where measured meteorological data are unavailable.
\end{abstract}

"zanandraboff@gmail.com 
Keywords: need for irrigation; underground dripping; weather forecast.

\section{INTRODUÇÃO}

As atividades agrícolas demandam grandes quantidades de água e, sendo cada vez mais preocupante a sua escassez, são necessários esforços no desenvolvimento de pesquisas e tecnologias visando a maximização de seu uso na produção agrícola, especialmente na agricultura irrigada. Neste sentido, é necessário a adoção de sistemas de irrigação eficientes manejados adequadamente, considerando as especificidades de solo, cultura e clima.

A deficiência hídrica é uma situação comum a muitas culturas e afeta a maioria das regiões produtoras no Brasil. De acordo com Bergamaschi \& Matzenauer (2014), a região Nordeste do Brasil, por secas prolongadas, e as regiões Sul e Sudeste, por estiagens frequentes, têm grande variabilidade na produção agrícola. Sendo o milho uma das culturas mais afetadas pela variabilidade no regime pluviométrico, devido a sua sensibilidade ao déficit hídrico.

Para Matzenauer et al. (2002), a maior parte do Rio Grande do Sul apresenta fortes restrições ao cultivo do milho em decorrência do déficit hídrico, que abrange toda a metade sul e o extremo oeste do Estado. Mesmo nas regiões mais ao norte, onde se encontram as áreas consideradas preferenciais pelo zoneamento climático, as médias de precipitação não atendem às necessidades da cultura, e a ocorrência de estiagens também afeta a produção de milho. Resultados obtidos por Bergamaschi et al. (2006), em estudos conduzidos em Eldorado do Sul, RS demonstram que, o déficit hídrico tem maior impacto sobre o rendimento de grãos de milho quando ocorre na fase de florescimento.

Dentre os métodos de irrigação, a irrigação localizada pelo sistema de gotejamento é uma tecnologia que permite maior controle sobre a quantidade de água aplicada, melhorando a eficiência de seu uso na agricultura irrigada. De acordo com Abuarab et al. (2013), a utilização do sistema de irrigação por gotejamento subterrâneo aumenta a eficiência da irrigação, permite uma boa mecanização e o uso de água residuária. Entretanto, apesar das inúmeras vantagens associadas à irrigação por gotejamento, a sua implantação muitas vezes é limitada pelo elevado custo de implantação e manutenção (BOAS et al., 2011; MARTINS et al., 2016).

O manejo da irrigação, ou seja, a definição de quando e quanto irrigar, é uma tarefa complexa, pois envolve inúmeras variáveis, relacionadas ao solo, ao clima, a cultura e ao equipamento de irrigação. A literatura que é base para a definição de muitos desses parâmetros é o boletim FAO 56 (ALLEN et al., 1998), que apresenta a metodologia de cálculo da evapotranspiração da cultura (ETc) a partir da evapotranspiração de referência (ETo) e do coeficiente de cultivo (Kc). Além disso, são necessários vários parâmetros meteorológicos, tornando a disponibilidade desses dados meteorológicos medidos limitada, dificultando a aplicação dessa metodologia em área agrícola.

Nestes casos, a utilização de dados da previsão do tempo, que são amplamente disponíveis por diferentes portais de meteorologia e diferentes meios de comunicação, podem ser uma alternativa para estimativa da ETo (XU et al., 2012; SILVA et al., 2010; ER-RAKI et al., 2010; ISHAK et al., 2010; CAI et al., 2007; CAI et al., 2009; PERERA et al., 2013), e a partir desta, a realização da recomendação da necessidade de irrigação, seguindo a metodologia proposta por Allen et al. (1998).

Assim, objetivou-se com o presente trabalho avaliar o rendimento de grãos do milho irrigado por gotejamento subterrâneo instalado em duas profundidades e dois espaçamentos entrelinhas e comparar o cálculo da necessidade hídrica da cultura milho a partir de dados meteorológicos previsão do 
tempo e medidos no local para o cálculo da

\section{MATERIAL E MÉTODOS}

\section{Experimento de campo}

$\mathrm{O}$ experimento foi realizado no ano agrícola 2013/14, na área experimental do Instituto Federal Farroupilha Campus Júlio de Castilhos, na cidade de Júlio de Castilhos, estado do Rio Grande do Sul, Brasil. O clima da região é o Cfa, conforme a classificação de Köppen, em altitude de aproximadamente $513 \mathrm{~m}$, chuva média anual de $1450 \mathrm{~mm}$ a $1650 \mathrm{~mm}$, temperatura média mínima anual de $12^{\circ} \mathrm{C}$ a $14^{\circ} \mathrm{C}$, temperatura média máxima anual de $23^{\circ} \mathrm{C}$ a $25^{\circ} \mathrm{C}$, respectivamente. $\mathrm{O}$ solo da área experimental foi classificado como Argissolo Vermelho Distrófico Típico conforme Embrapa (2013).

O delineamento experimental utilizado foi o inteiramente casualizado, no esquema fatorial $2 \times 2$, com três repetições, sendo o fator " $\mathrm{A}$ " duas profundidades de instalação do tubogotejador: (i) $20 \mathrm{~cm}$ e (ii) $40 \mathrm{~cm}$. O fator "D" contou de dois espaçamentos entrelinhas dos tubogotejadores: (i) $90 \mathrm{~cm}$ e (ii) $135 \mathrm{~cm}$. As unidades experimentais possuíram as dimensões de 4 x $5 \mathrm{~m}\left(20 \mathrm{~m}^{2}\right)$.

A cultivar de milho Dow 2B655, foi semeada no dia 30 de outubro de 2014, com espaçamento entre linhas de $0,45 \mathrm{~m}$ e população média de 70.000 plantas $\mathrm{ha}^{-1}$. A área havia sido cultivada com aveia no inverno, o que resultou em uma produção de biomassa de aproximadamente 3 toneladas $\mathrm{ha}^{-1}$.

A fertilização do solo do experimento foi realizada com base na análise química do solo, seguindo as indicações da Comissão de Fertilidade do Solo do Rio Grande do Sul e de Santa Catarina (2004), com uma expectativa de produção de $12000 \mathrm{Kg} \mathrm{ha}^{-1}$ de milho.

Para a instalação dos tubogotejadores foram escavadas manualmente, com auxílio de pá e picão, valetas com profundidade e espaçamento determinados em função dos tratamentos propostos. Utilizou-se gotejadores autocompensantes
ETo.

com vazão de $3,81 \mathrm{~h}^{-1}$ espaçados na linha a cada $40 \mathrm{~cm}$.

Para o manejo da irrigação, utilizouse os seguintes parâmetros: as irrigações foram realizadas quando a ETc atingia o valor acumulado de $25 \mathrm{~mm}$. Sendo que, na ocorrência de chuvas superiores a $25 \mathrm{~mm}$, zerava-se a ETc acumulada. Quando as chuvas eram inferiores a $25 \mathrm{~mm}$, subtraíase a chuva da ETc acumulada. A ETc foi obtida a partir da ETo calculada pelo método FAO - PM e do Kc, conforme Allen et al. (1998). Os dados meteorológicos diários para o cálculo da ETo foram obtidos de uma estação meteorológica automática, instalada em área gramada, localizada a $20 \mathrm{~m}$ local do experimento.

Para as determinações da área foliar da cultura, duas plantas foram selecionadas aleatoriamente dentro de cada parcela. Essa determinação foi realizada em quatro datas, respectivamente, nos dias: 03/12/2013 aos 34 dias após a semeadura (DAS), 18/12/2013 aos 49 DAS, 08/01/2014 aos 70 DAS e no dia 03/02/2014 aos 96 DAS. O índice de área foliar (IAF) foi calculado pela razão entre a área foliar fotossinteticamente ativa da planta e a área superficial de solo ocupada pela mesma. Ao final do ciclo de cultivo do milho realizou-se a colheita de seis plantas de cada parcela, avaliando-se o e rendimento de grãos de cada unidade experimental, com correção da umidade dos grãos para $13 \%$.

As variáveis obtidas (IAF e rendimento de grãos) foram submetidas à análise estatística. A análise da variância e comparação de médias (teste de Tukey) foram realizadas em nível de $5 \%$ de probabilidade de erro, utilizando-se o programa estatístico SAS.

\section{Estimativa da ETo com dados da previsão do tempo}

Durante o ciclo de desenvolvimento da cultura do milho, foram anotados 
diariamente $(10: 00 \quad$ h) do site: http://www.tempoagora.com.br/, os dados da previsão do tempo da temperatura máxima do ar (Tmax), da temperatura mínima do ar (Tmin), da umidade relativa máxima do ar (URmax), da umidade relativa mínima do ar (URmin) e da velocidade do vento (v.v), para o dia seguinte, ou seja, com um dia de antecedência ao dia observado. Utilizou-se o método FAO - PM para o cálculo da ETo. Para isso, os valores de temperatura média do ar e a umidade relativa média do ar, foram obtidos a partir da média entre os valores máximos e mínimos do dia. A Rs foi estimada a partir da equação proposta por Hargreaves (HARGREAVES \& SAMANI, 1982).

$\mathrm{RS}=\mathrm{K}_{\mathrm{RS}}\left(\mathrm{T}_{\max }-\mathrm{T}_{\min }\right)^{0,5} \mathrm{R}_{\mathrm{a}}$

Em que:

$\mathrm{R}_{\mathrm{S}}$ : radiação solar ou radiação de onda curta $\left(\mathrm{MJm}^{-2} \mathrm{~d}^{-1}\right)$

$\mathrm{R}_{\mathrm{a}}$ : radiação extraterrestre $\left(\mathrm{MJ} \mathrm{m}^{-2} \mathrm{~d}^{-1}\right)$

$\mathrm{K}_{\mathrm{RS}}: 0,16$, é o coeficiente empírico de ajuste da Rs para regiões continentais.

Os valores de ETo prev foram comparados com os valores de ETo. A verificação da precisão das estimativas da ETo prev, foi realizada a partir do RMSE
(Equação 2), que dá a medida do erro médio que está sendo cometido. $\mathrm{Na}$, equação as siglas $\mathrm{Oi}$ e $\mathrm{Pi}(\mathrm{i}=1,2, \ldots, \mathrm{n})$ representam pares de valores ETo obtidos com dados meteorológico medidos no local e os valores de ETo estimados com os dados da previsão metrológica, respectivamente.

$$
\mathrm{RMSE}=\left[\frac{\sum_{\mathrm{i}=1}^{\mathrm{n}}\left(\mathrm{P}_{\mathrm{i}}-\mathrm{O}_{\mathrm{i}}\right)^{2}}{\mathrm{n}}\right]^{0.5}
$$

\section{Estimativa da necessidade de irrigação da cultura do milho a partir da ETo prev}

A estimativa da necessidade da irrigação da cultura do milho com os dados da ETo prev, baseou-se nos mesmos critérios utilizados para o manejo da irrigação do experimento de campo. Considerou-se para a recomendação da irrigação, a ETc acumulada de $25 \mathrm{~mm}$, descontando-se as chuvas do período. Considerou-se duas situações para o cômputo das chuvas: (i) utilizando as chuvas observadas (medidas); (ii) utilizando as chuvas estimadas pela previsão do tempo (chuvas prev).

\section{RESULTADOS E DISCUSSÃO}

A figura 1 apresenta as chuvas, as irrigações e a ETc observadas durante a realização do experimento de campo com a cultura do milho.

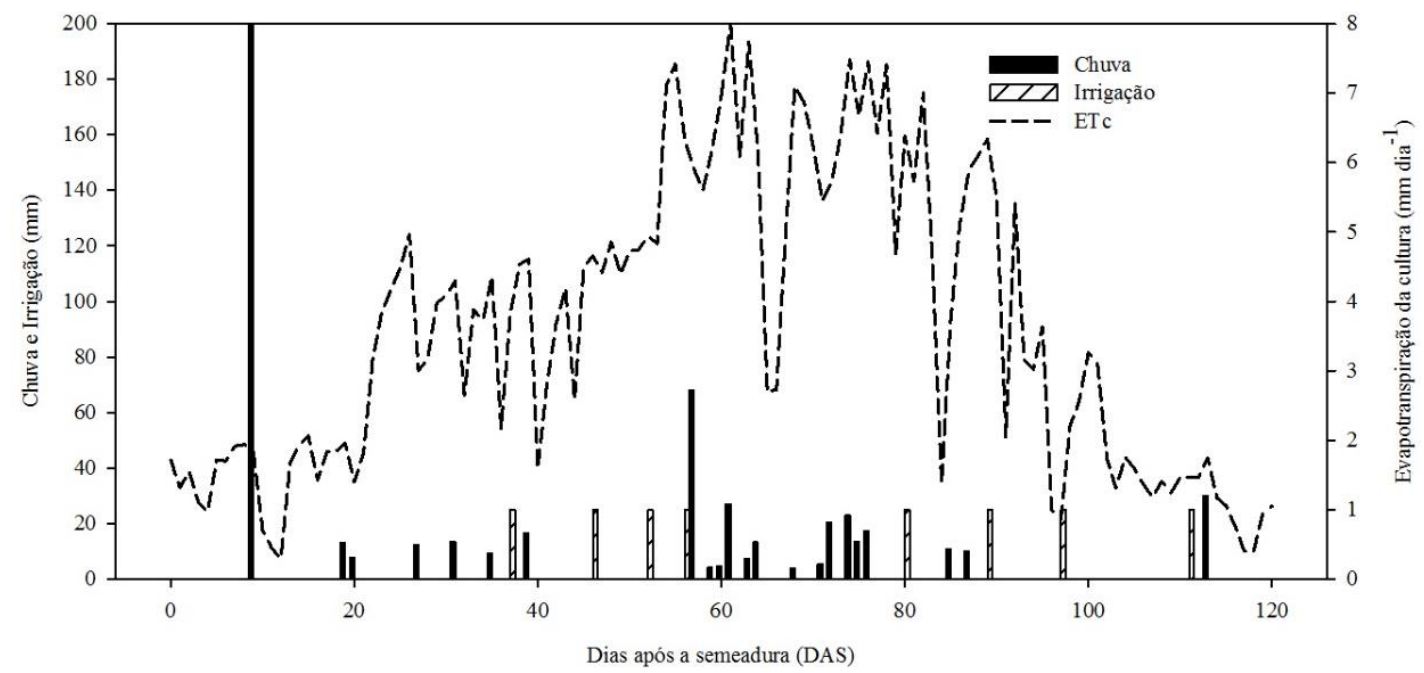


Figura 1. Chuvas, irrigações e evapotranspiração da cultura observadas durante o ciclo de desenvolvimento do milho.

Durante o ciclo de desenvolvimento da cultura, a precipitação acumulada foi de $530 \mathrm{~mm}$, suficiente para suprir a ETc acumulada que foi de $432 \mathrm{~mm}$. Todavia, devido a irregularidade das chuvas, foram necessárias oito irrigações suplementares, totalizando $200 \mathrm{~mm}$. Destas oito irrigações, cinco, foram realizadas no período compreendido entre os 37 e 90 dias DAS, em que ETc média foi de $5,75 \mathrm{~mm} \mathrm{dia}^{-1}$, refletindo a evolução do ciclo de cultivo para estádios fenológicos com maior demanda hídrica. O valor máximo de ETc de $8 \mathrm{~mm} \mathrm{dia}^{-1}$ foi observado aos 61 DAS, em que as plantas estavam em pleno pendoamento e início do embonecamento, apresentando o máximo IAF, constatado na terceira observação de campo, realizada aos 70 DAS (Figura 2). De acordo com a Embrapa (2010), o milho de variedade de ciclo médio, cultivado para a produção de grãos secos, consome de 380 a $550 \mathrm{~mm}$ de água em seu ciclo completo, sendo que o período de máxima exigência hídrica é na fase do embonecamento ou um pouco depois dele.

Os valores de IAF observados (Figura 2) foram superiores ao considerado crítico (entre 3 e 5) por Francinelli \& Dourado Neto (2000), para a garantia de um bom desenvolvimento das plantas de milho e do potencial de interceptação de energia radiante. Não havendo diferenças estatísticas entre os tratamentos para o IAF até a terceira observação. Tal resultado pode ser atribuído a boa distribuição de chuvas na fase inicial de desenvolvimento da cultura (Figura 1), permitindo um molhamento uniforme das camadas inicias do perfil do solo e, com isso, um bom estabelecimento da cultura.

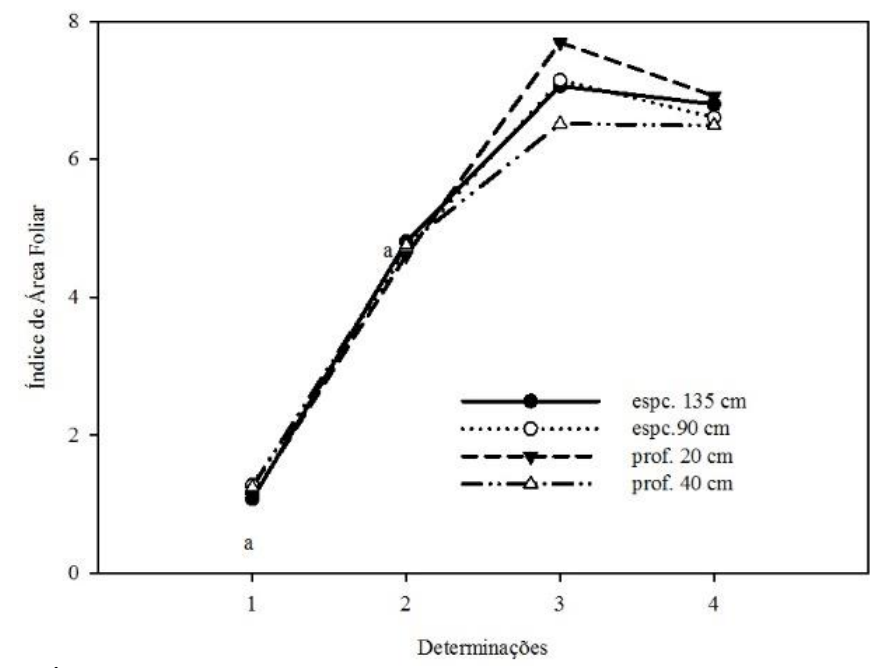

Figura 2. Índice de Área Foliar de plantas de milho irrigadas com sistema de gotejamento subterrâneo em dois espaçamentos $(90$ e $135 \mathrm{~cm})$ e duas profundiades $(20$ e $40 \mathrm{~cm})$.

Na terceira observação, aos 70 DAS, em que o IAF das plantas foi máximo, as plantas irrigadas com tubogotejadores instalados a $40 \mathrm{~cm}$ de profundidade apresentaram maior IAF que as plantas irrigadas com tubogotejadores instalados a $20 \mathrm{~cm}$ de profundidade. Esse resultado indica que, uma irrigação mais superficial $(20 \mathrm{~cm})$ na fase em que a cultura apresenta o sistema radicular mais profundo, pode ter ocasionado um menor suprimento hídrico do solo. Para Bruce et al. (2002), quando o milho encontra déficit hídrico, há redução da expansão foliar e, consequentemente, um declínio na fotossíntese por planta. Resultado similar ao obtido nesse trabalho foi obtido por Douh \& Boujelben (2011), avaliado os efeitos da irrigação por gotejamento superficial e subterrâneo nos parâmetros agronômicos de milho (Zea mays L.) sob condição climática da Tunisina, obtendo os maiores valores de 
área foliar por planta de $0,3987 \mathrm{~m}^{2}$ na profundidade de instalação do tubogotejador de $0,35 \mathrm{~m}$, em comparação as demais profundidades de instalação avaliadas de $0 \mathrm{~m}, 0,05 \mathrm{~m}, 0,20 \mathrm{~m}$ e $0,5 \mathrm{~m}$.

Nessa fase do ciclo de desenvolvimento em questão (70 DAS), em que a cultura iniciava seu período reprodutivo, existe uma maior sensibilidade ao déficit hídrico que no período vegetativo. $\mathrm{O}$ milho é relativamente tolerante ao déficit hídrico durante a fase vegetativa, porém demonstra extrema sensibilidade, com decréscimo no rendimento de grãos, se esse déficit ocorrer na fase reprodutiva (BERGAMASCHI et al. 2006; BERGAMASCHI et al. 2004). Martins et al. (2010), afirmam que, a deficiência hídrica pode ocasionar perturbações fisiológicas e morfológicas que prejudicam o desenvolvimento e o rendimento da cultura do milho.
Com isso, observa-se na figura 3 , que as plantas irrigadas com tubogoteadores instalados a $40 \mathrm{~cm}$ de profundidade, apresentaram rendimento de grãos mais elevado, sendo este de $11895,34 \mathrm{~kg} \mathrm{ha}^{-1}$, em comparação as plantas irrigadas com tubogotejadores enterrados a $20 \mathrm{~cm}$ de profundidade, que apresentaram um rendimento de 10006,29 $\mathrm{kg} \mathrm{ha}^{-1}$. Já, entre os espaçamentos entre tubogotejadores $(90$ e $135 \mathrm{~cm}$ ), não foi observada diferenças estatísticas para o rendimento de grãos do milho, sendo o valor médio obtido de 10950,80 kg ha ${ }^{-1}$ (Figura 3). Douh e Boujelben (2011), avaliado os efeitos da irrigação por gotejamento superficial e subterrâneo nos parâmetros agronômicos de milho (Zea mays L.) sob condição climática da Tunisina, obtiveram o rendimento de grãos máximo de $13400 \mathrm{~kg}$ $\mathrm{ha}^{-1}$ utilizando a profundidade de instalação do tubogotejador de $0,35 \mathrm{~m}$.

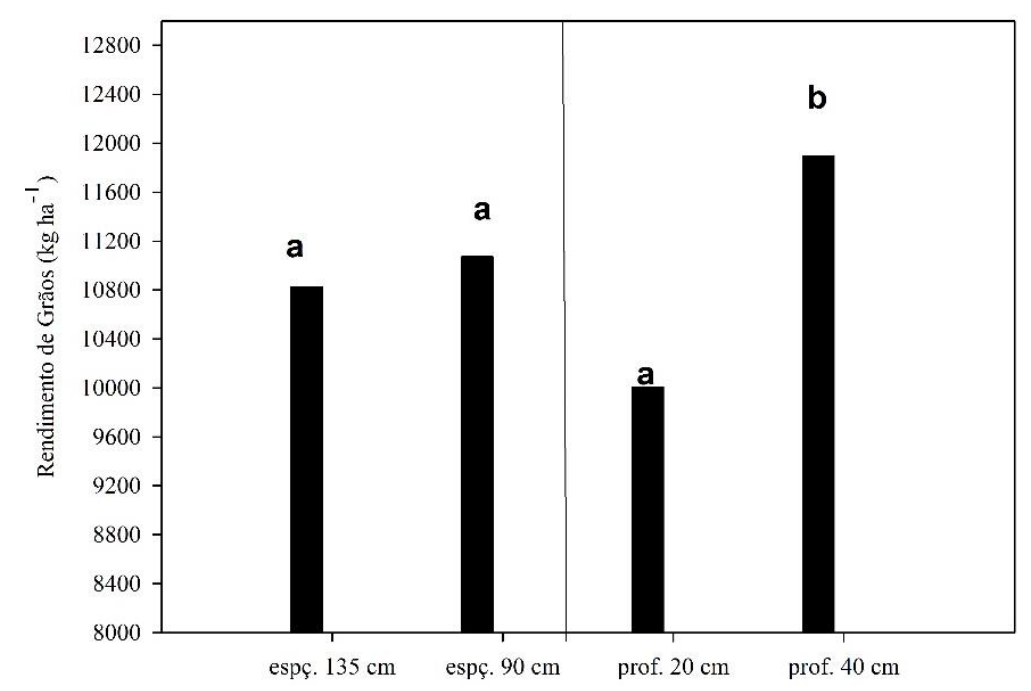

Figura 3. Rendimento de grãos do milho irrigado com sistema de gotejamento subterrâneo em dois espaçamentos ( 90 e $135 \mathrm{~cm}$ ) e duas profundiades (20 e $40 \mathrm{~cm}$ ).

O fato de não haver diferenças significativas no rendimento de grãos do milho irrigado com diferentes espaçamentos entrelinhas de tubogotejadores, é importante no ponto de vista da redução nos custos de instalação do sistema, podendo-se recomendar o espaçamento de $135 \mathrm{~cm}$, para a redução dos custos com a tubulação lateral. De acordo com Bozkurt et al. (2006), os custos da tubulação lateral representam aproximadamente $45 \%$ do custo total de um sistema de irrigação para a cultura do milho, e a substituição de uma linha lateral de gotejamento por linha de cultivo para duas linhas de cultivo por linha de gotejamento, resulta em uma considerável redução nos custos.

$\mathrm{Na}$ figura 4, estão apresentados os valores de ETo obtidos durante o ciclo de desenvolvimento do milho e os valores de ETo prev obtidos para o período. 


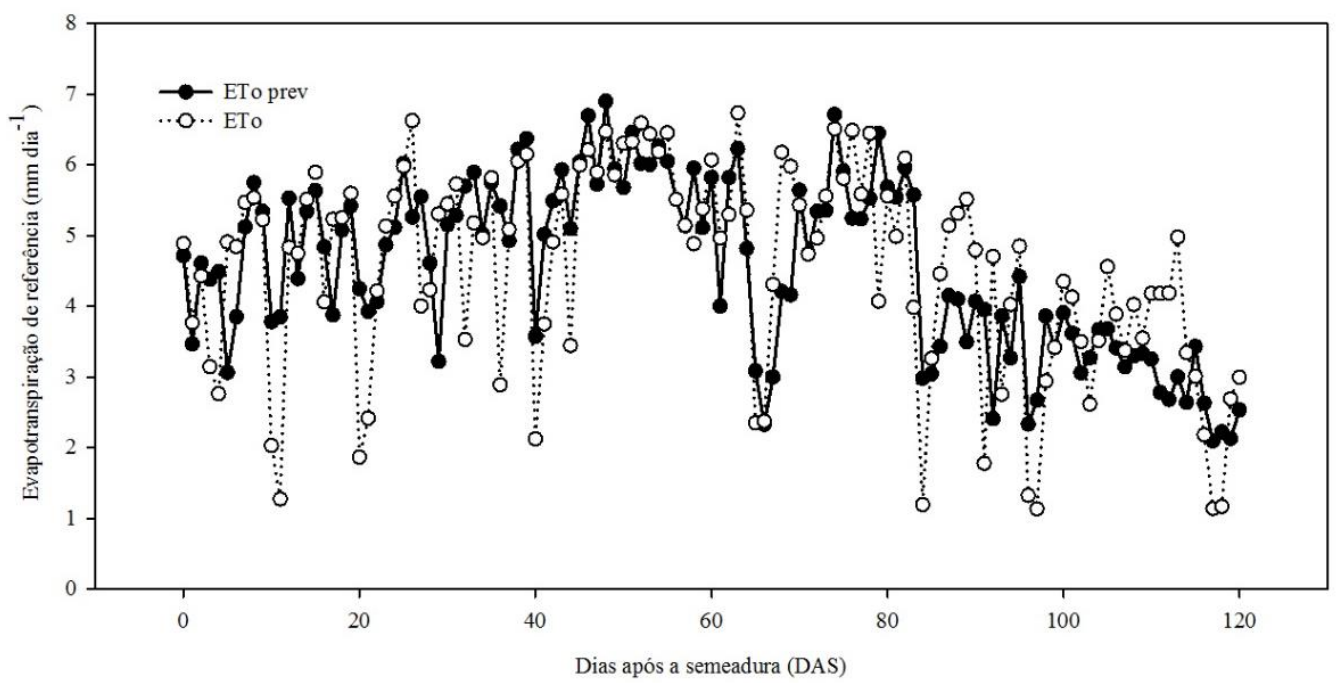

Figura 4. Valores diários de evapotranspiração de referência obtidos com dados meteorológicos medidos no local (ETo) e valores de evapotranspiração de referência estimados com dados da previsão do tempo (ETo prev), durante o ciclo de desenvolvimento do milho.

Observa-se uma boa concordância entre os valores de ETo e os valores de ETo prev. O valor de RMSE obtido de $1,05 \mathrm{~mm} \mathrm{dia}^{-1}$ (Figura 5), foi semelhante ao observados por Silva et al. (2010), que obtiveram valores entre 0,67 e $1,15 \mathrm{~mm}$ $\mathrm{dia}^{-1}$, estimando a ETo (FAO PM), utilizando dados numéricos da previsão do tempo obtidos do modelo MM5 (Mesocale Model versão 5), em diferentes locais, na região central do Chile. Trabalhando com um banco de dados maior, Perera et al. (2013), obtiveram valores de RMSE menores que os observados nesse trabalho. Estes autores, estimaram a ETo (FAO PM) no período compreendido entre 1996 e 2012, para um a nove dias de antecedência ao dia observado para Shepparton na Austrália e obtiveram valores de RMSE variando entre 0,65 e 1,26 $\mathrm{mm} \mathrm{dia}^{-1}$. Resultado semelhante foi obtido por Cai et al. (2009), em estudo conduzido na China, durante dois anos agrícolas para a cultura do trigo, que obtiveram um RMSE de $0,77 \mathrm{~mm} \mathrm{dia}^{-1}$. 


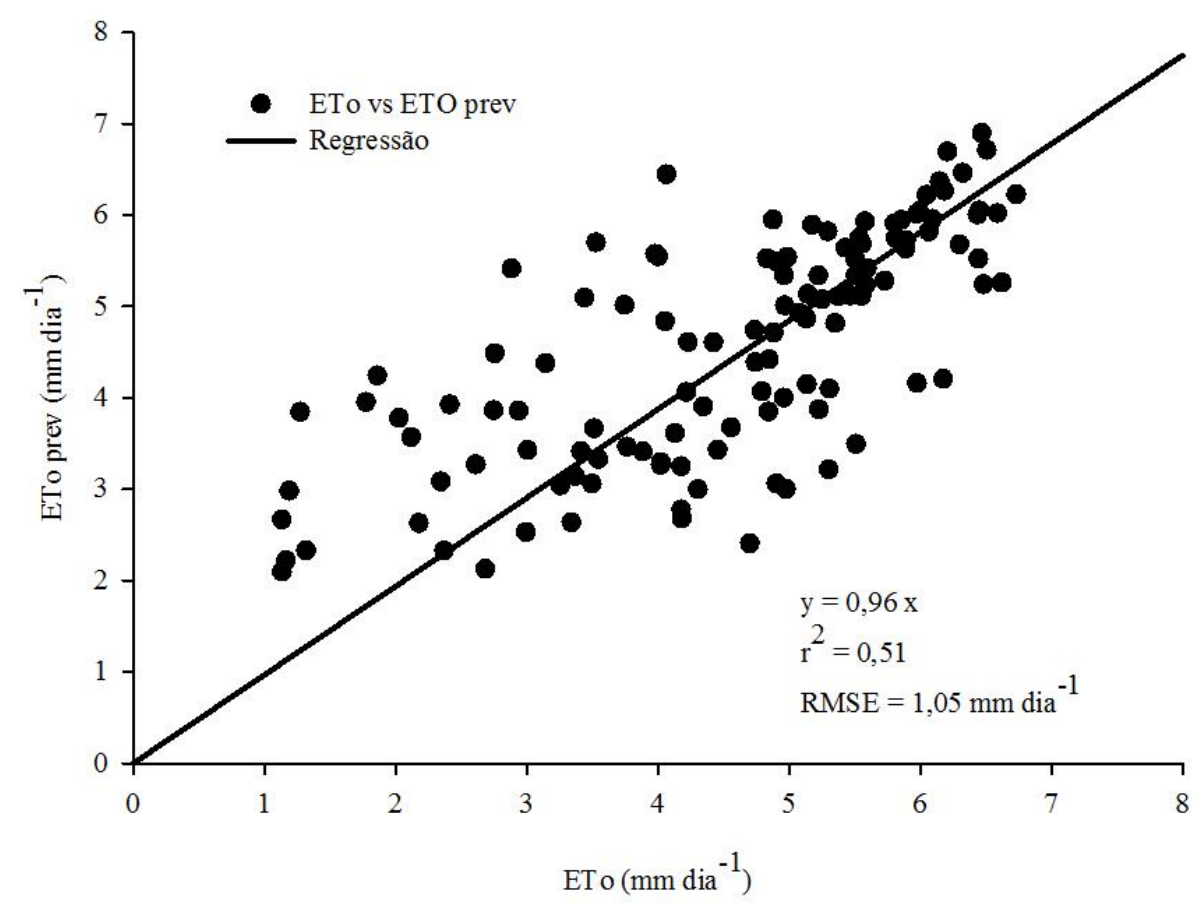

Figura 5. Comparação entre os valores diários de evapotranspiração de referência obtidos com dados meteorológicos medidos no local (ETo) e valores de evapotranspiração de referência estimados com dados da previsão do tempo (ETo prev), durante o ciclo de desenvolvimento do milho.

Os resultados das irrigações efetuadas a partir da ETo e das chuvas observadas e das irrigações estimadas a partir da ETo prev e das chuvas observadas e previstas, são apresentados na figura 6 . 


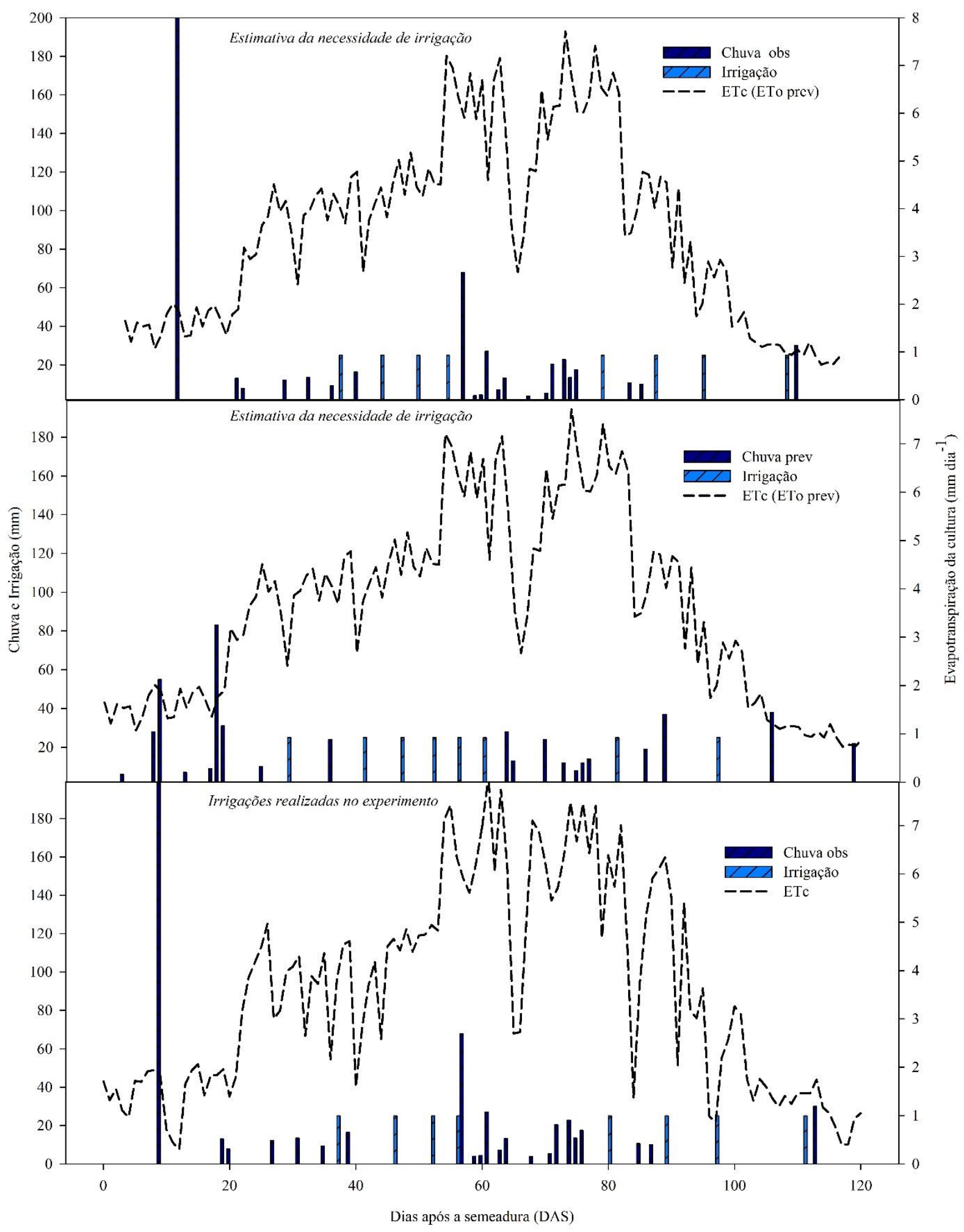

Figura 6. Resultado da estimativa da irrigação para a cultura do milho realizada a partir da evapotranspiração de referência calculada com dados da previsão do tempo para Júlio de Castilhos, RS, em duas situações de chuva: observada e estimada pela previsão.

Observa-se, para ambas as situações de chuva (observada e estimada pela previsão do tempo), que a utilização da ETo prev para o cálculo da ETc resulta em uma estimativa de oito irrigações suplementares ao longo do ciclo de desenvolvimento da cultura do milho, totalizando $200 \mathrm{~mm}$ (Figura 6). Esse 
resultado é igual ao aplicado a campo, quando se utilizou os valores de ETo calculados com dados meteorológicos medidos no local para a obtenção da ETc (Figura 1).

Quando se utilizou a ETo prev e as chuvas observadas (Figura 6), a distribuição das irrigações estimadas foi praticamente a mesma da realizada no campo (Figura 1), com a antecipação de um ou dois dias em comparação a aplicada. Todavia, quando se utiliza a ETo prev e as chuvas da previsão, ocorre uma diferença maior na distribuição das irrigações (Figura 6), pois houveram dias que a previsão estimou chuva e que a mesma não aconteceu e vice e versa, refletindo em diferenças nos valores acumulados. As chuvas observadas somaram $530 \mathrm{~mm}$ e as previstas somaram $480 \mathrm{~mm}$. Neste caso, para se ter uma recomendação precisa sobre a utilização das chuvas da previsão do tempo no manejo da irrigação, existe a necessidade de estudos mais aprofundados, com a medição do conteúdo de água no solo para se averiguar os impactos na disponibilidade de água no solo as plantas.

A utilização de dados meteorológicos da previsão do tempo para o cálculo da

\section{CONCLUSÕES}

O máximo rendimento de grãos de milho de $1.1895,34 \mathrm{~kg} \mathrm{ha}^{-1}$ foi obtido utilizando a profundidade de instalação do tubogotejador de $40 \mathrm{~cm}$ em comparação ao rendimento de grãos de $10006,29 \mathrm{~kg} \mathrm{ha}^{-1}$ obtido com a utilização da profundidade de instalação do tubogotejador de $20 \mathrm{~cm}$. O rendimento médio de grãos de milho foi de $1.0950,80 \mathrm{~kg} \mathrm{ha}^{-1}$ com a utilização dos espaçamentos entrelinhas de instalação do tubogotejador de 90 e $135 \mathrm{~cm}$

O RMSE de 1,05 $\mathrm{mm} \mathrm{dia}^{-1}$ indicou

\section{REFERÊNCIAS}

ALLEN, R.G.; PEREIRA, L.S.; RAES, D.; SMITH, M. Crop Evapotranspiration: Guidelines for computing crop requirements. FAO, Irrigation and
ETo em tempo futuro é viável, e que a sua aplicação para o manejo da irrigação em tempo real e futuro pode trazer inúmeros benefícios aos produtores irrigantes. Um exemplo prático dessa aplicação é o fato dos produtores anteciparem irrigações (sem defasagens na lâmina de irrigação) evitando que vários equipamentos operem ao mesmo tempo, programar o manejo fitossanitário e nutricional das plantas de acordo com a prática de irrigação, entre outras vantagens, contribuindo para $\mathrm{o}$ gerenciamento da atividade irrigada e para a maior eficiência na utilização dos recursos naturais e demais insumos agrícolas.

Além disso, a proposta desse estudo pode ser aplicada em locais em que a disponibilidade de dados meteorológicos medidos é limitada, como é o caso de regiões não cobertas pela rede de observação meteorológica (INMET CPTEC/INPE), que necessitariam de estações meteorológicas automáticas particulares, o que nem sempre é possível, em razão do seu custo inicial e da infraestrutura necessária.

precisão na estimativa da ETo a partir de dados meteorológicos da previsão do tempo em comparação a ETo calculada com dados meteorológicos medidos.

O número de irrigações recomendadas ao longo do ciclo de desenvolvimento do milho com a ETo calculada com dados meteorológicos medidos no local foi igual ao número de irrigações estimadas com a ETo calculada com dados da previsão meteorológica ( 8 irrigações).

Drainage Paper No. 56, FAO, Rome, Italy, pp.300 1998.

BERGAMASCHI, H.; DALMAGO, G.A.; BERGONCI, J.I.; BIANCHI, C.A.M.; 
MÜLLER, A.G.; COMIRAN, F.; HECKLER, B.M.M. Distribuição hídrica no período crítico do milho e produção de grãos. Pesquisa Agropecuária Brasileira, Brasília-DF, v.39, p.831-839, 2004.

BERGAMASCHI, H.; MATZENAUER, R. O milho e o clima. Porto Alegre: Emater/RS-Ascar, 84 p. il, 2014.

BOAS, R.C.V.; PEREIRA, G.M.; REIS, R.P.; JUNIOR, J.A. de L.; CONSONI, R. Viabilidade econômica do uso do sistema de irrigação por gotejamento na cultura da cebola. Ciência Agrotecnologia, Lavras, MG-Brasil, v. 35, n. 4, p. 781-788, 2011.

BOZKURT, Y.; YAZAR, A.; GENÇEL, B.; SEZEN, M. S. Optimum lateral spacing for dripirrigated corn in the Mediterranean Region of Turkey. Agricultural water management, Amsterdã, v. 85, p. 113120, 2006.

BRUCE, W. B.; EDMEADES, G. O.; BARKER, T. C. Molecular and physiological approaches to maize improvement for drought tolerance. Journal of Experimental Botany, London, v. 53, n. 66, p. 13-25, 2002.

CAI, J. B.; LIU, Y; XU, D.; PAREDES, P.; PEREIRA, L. S. Simulation of the soil water balance of wheat using daily weather forecast messages to estimate the reference evapotranspiration. Hydrology and Earth System Sciences, European GeosciUnion. ense v.13, p.1045-1059, 2009.

CAI, J.; LIU, Y.; TINGWU, L.; PEREIRA, L. S. Estimating reference evapotranspiration with FAO PenmanMonteith equation using daily weather forecast messages. Agriculture and Forest Meteorology, Amsterdã, v. 145, n. 01/02, p. 22-35, 2007.

DOUH, B.; BOUJELBEN, A. Effects of surface and subsurface drip irrigation on agronomic parameters of maize (Zea mays L.) under Tunisian climatic condition.
Journal of Natural Product and Plant

Resources, Indian,p. 8-14, 2011.

EMBRAPA. Cultivo do Milho Irrigação. Versão Eletrônica. Brasília, $6^{\mathbf{a}}$ edição, 2010.

EMBRAPA. Sistema brasileiro de classificação de soos. 3.ed. Brasília, 2013. 353p.

ER-RAKI, S.; CHEHBOUNI, A.; KHABBA, S.; SIMONNEAUZ, V.; JARLAN, L.; OULDBBA, A. Assessment of reference evapotranspiration methods in semi-arid regions: can weather forecast data be used as a alternate of ground meteorological parameters? Journal of Arid Environments, Amsterdã, v.3, p. 110, 2010.

FANCELLI, A. L.; DOURADO NETO, D. Produção de milho. Guaíba: Agropecuária, 2000. 360p.

HARGREAVES, G.H., SAMANI, S. Estimating potential evapotranspiration. Journal of Irrigation and Drainage Engineering, Reston - EUA, 108-3, 225230,1982 .

ISHAK, A.M., BRAY, M.; REMESAN, R., HAN, D. Estimating reference evapotranspiration using numerical weather modelling. Hydrological Processes, Chichester, 24, 3490-3509, 2010.

MARTINS, J. D.; CARLESSO, R.; KNIES, A. E.; OLIVEIRA, Z. B.; BROETTO, T.; RODRIGUES, G. C. Potencial hídrico foliar em milho submetido ao déficit hídrico. Irriga, Botucatu, Botucatu - SP, v. 15, n. 3, p. 324-334, julho-setembro 2010.

MARTINS, J. D.; PETRY, M. T.; RODRIGUES, G. C.; CARLESSO, R. Viabilidade econômica da irrigação deficitária em milho irrigado por gotejamento. Irriga, Botucatu, Botucatu - 
SP,Edição Especial, Grandes Culturas, p. 150-165, 2016.

MATZENAUER, R.; BERGAMASCHI, H.; BERLATO, M.A.; MALUF, J.R.T.; BARNI, N.A.; BUENO, A.C.; DIDONÉ, I.A.; ANJOS, C.S.; MACHADO, F.A.; SAMPAIO, M.R. Consumo de água e disponibilidade hídrica para milho e soja, no Rio Grande do Sul. Porto Alegre: Fepagro. 105p. (Boletim Fepagro, 10), 2002.

PERERA, K.; WETERN, A.; NAWARATHNA, B.; GEORGE, B. Forecasting Daily Reference Evapotranspiration for Shepparton, Victoria, Australia using Numerical Weather Prediction outputs. In 20th International Congress on Modelling and Simulation, Adelaide, Australia, 1-6 December 2013.

SILVA, D.; MEZA, F.J.; VARAS, E. Estimating reference evapotranspiration (ETo) using numerical weather forecast data in central Chile. Journal of Hydrology. v. 382, p. 64-71, 2010.

XU, C-Y.; CHEN, D. Comparison of seven models for estimation of evapotranspiration and groundwater recharge using lysimeter measurement data in Germany. Hydrological Processes, Chichester, v. 19, n. 18, p. 3717- 3734, 2005.

XU. J.Z; PENG, S. Z; YANG, S. H. LUO, Y. F. WANG, Y. J. Predicting daly evapotranspiration in a Humid region of China by the locally calibrated HargreavesSamani equation using weather forecast data. Journal of Agricultural Science and Technology, Tehran, Islamic Republic of Iran. v.14, p.1331-1342, 2012. 